\title{
Hetero-resistencia en Staphylococcus aureus con resistencia intermedia a vancomicina, ¿susceptible o resistente?
}

\author{
Heteroresistance in Vancomycin-Intermediate Staphylococcus aureus (VISA), \\ susceptible or resistant?
}

La historia de Staphylococcus aureus y los antibacterianos ha sido de una guerra sin fin de ataques y respuestas. Probablemente desde tiempos bíblicos, $S$. aureus ya existía produciendo enfermedad sin contraparte alguna y recién, en 1880 , se le reconoce como tal y recibe el nombre que mantiene hasta la actualidad ${ }^{1}$. En el año 1940 recibe el primer impacto cuando aparece la penicilina y en 1946 responde precozmente con resistencia a penicilina mediada por penicilinasas. En respuesta a ello, vancomicina se aísla en 1953, aunque se dispone para uso clínico recién en 1958 y en el año 1959 aparecen también como alternativa terapéutica las penicilinas resistentes a penicilinasa. Vancomicina rápidamente pierde la batalla como indicación clínica frente a las penicilinas dado sus dificultades de administración y toxicidades. Algún tiempo después, en el año 1961, aparece la resistencia a meticilina y, en relación a ello, vancomicina reaparece como única alternativa terapéutica ${ }^{2}$. Sin embargo, no fue sólo hasta la década de los 80 en que $S$. aureus resistente a meticilina (SARM o su sigla en inglés: MRSA) toma una importancia central en la epidemiología hospitalaria; vancomicina recobra su relevancia en el arsenal terapéutico para tratar el principal agente etiológico de infecciones asociadas a la atención de salud, manteniendo entonces, tanto la bacteria como su único agente terapéutico, un rol fundamental durante al menos tres décadas.

La aparición y posterior expansión de Enterococcus resistente a vancomicina (ERV) en 1988, fue el concreto anuncio que la resistencia a vancomicina podía ocurrir y gatillante del temor en la comunidad infectológica de que esta resistencia se traspasase a $S$. aureus produciendo un desastre, cuando en esos momentos no se contaba con otras alternativas para esta importante resistencia bacteriana $^{3}$. Previamente, ya en la década de los 80 , se había demostrado en laboratorio que los genes Van (mediadores de alta resistencia a vancomicina) podían ser traspasados in vitro desde Enterococcus spp. a S. aureus ${ }^{4}$.

Finalmente el temor se hizo realidad. En 1998, Hiramatsu publica el primer caso de $S$. aureus con resistencia intermedia a vancomicina, lo cual eleva una alerta mundial ${ }^{5}$. Sin embargo, el mecanismo que se demostró en esta cepa fue un mecanismo no asociado a genes Van, como se pensaba iba a ocurrir, sino que estaba dado por un engrosamiento anormal de la cápsula de $S$. aureus frente a la exposición prolongada a vancomicina. Las cepas portadoras de este mecanismo, llamadas VISA (Vancomycin Intermedia Staphylococcus aureus) no tuvieron la diseminación que se temió en un principio. En el año 2002, en un paciente de Michigan se demostró el traspaso de genes Van in vivo de Enterococcus spp a $S$. aureus, confiriéndole a este último alta resistencia a vancomicina ( $\geq 16 \mu \mathrm{g} / \mathrm{mL}$ ), llamado VRSA (Vancomycin resistant Staphylococcus aureus $)^{6}$. Afortunadamente estas cepas también han sido oportunamente controladas y hasta la fecha sólo se han descrito muy pocos casos en el mundo. Finalmente, en 2014, en Brasil, Rossi reportó la primera cepa resistente a vancomicina en una cepa de SARM adquirido en la comunidad (en inglés denominado con la sigla CA-MRSA) mediada por genes $\mathrm{Van}^{7}$.

En el presente número de Revista Chilena de Infectología, en relación a una tesis de Magister de evaluación de SARM aislados en el Hospital de Concepción, Vega, González y cols., reportan una cepa de VISA heterosistente (hVISA) con CIM de $2 \mu \mathrm{g} / \mathrm{mL}$, adecuadamente confirmada por el equipo investigador. Las cepas VISA, ya sea hVISA o VISA propiamente tal, mantienen el mismo mecanismo de resistencia, pero difieren en sus puntos de corte, mientras en las hVISA los puntos de corte son 1-2 $\mu \mathrm{g} / \mathrm{mL}$ (rango susceptible), las cepas VISA tienen puntos de corte de 4-8 $\mu \mathrm{g} / \mathrm{mL}$ (rango intermedio). Independientemente de que la CIM esté en categoría susceptible o intermedia, estas cepas se asocian a fracaso terapéutico y de hecho, representan la presencia de sub-poblaciones que pueden crecer en medios con $2 \mu \mathrm{g} / \mathrm{mL}$ de vancomicina ${ }^{8}$. La cepa descrita en este estudio podría ser adicionalmente caracterizada por microscopia electrónica para observar el engrosamiento de la pared bacteriana. ¿Es esta la primera y única cepa de VISA que ha ocurrido en Chile? Probablemente no, pero sí es la primera cepa confirmada. De hecho, aislados de SARM con CIM $=2 \mu \mathrm{g} / \mathrm{mL}$ se ven ocasionalmente en nuestros laboratorios de microbiología. Esto puede ocurrir especialmente en poblaciones donde los pacientes están expuestos a tratamientos prolongados con vancomicina, por infecciones asociadas a la necesidad de preservar catéteres vasculares y prótesis de otro tipo. De hecho, esta cepa ocurrió en un paciente con CVC permanente para diálisis y uso prolongado de vancomicina, todos factores de riesgo descritos previamente en la literatura médica. En Chile hay estudios previos donde se reportan aislados de SARM con resistencia intermedia 
a vancomicina, con CIM hasta $8 \mu \mathrm{g} / \mathrm{mL}$. Sin embargo, no se reportaron estudios posteriores destinados a su confirmación ${ }^{9}$.

Afortunadamente las cepas de VISA como la aquí reportada no constituyen una amenaza mayor de propagación, más allá de las descrita tradicionalmente para $S$. aureus o dicha amenaza es quizás aún menor, dado que probablemente ocurre una pérdida de "fitness" bacteriano. Pese a esta segunda consideración, este evento debe mantenerse presente para evitar los factores de riesgo que favorecen la resistencia a vancomicina en determinados pacientes. Es probable que en países o en hospitales con limitaciones de recursos, dada la persistencia de manejo de pacientes con CVC permanentes, vamos a continuar viendo SARM, indicación de vancomicina por tiempos prolongados y resistencia a vancomicina como en este caso.

Esta cepa nos encuentra hoy mejor preparados que hace 15 años atrás. Tenemos más alternativas para tratar SARM, como las oxazolidinonas, daptomicina- que para esta cepa puede tener también limitaciones-, nuevos glicopéptidos y nuevas cefalosporinas recientemente aprobadas con acción sobre SARM. También se ha descrito en E.U.A. y Europa una disminución de la incidencia de SARM asociada al aumento de higiene de manos y mejores medidas de control de infecciones nosocomiales y quizás, a la ocurrencia de clones menos exitosos. Si bien seguiremos teniendo resistencia a oxacilina y en menor grado a vancomicina, es probable que con una visión optimista, en el futuro estos problemas vayan disminuyendo.

En Chile, salvo la excepción de unos pocos grupos, tenemos una deuda en investigación con las cocáceas grampositivas pues la gran mayoría de la investigación en resistencia bacteriana se ha centrado en los últimos años en bacilos gramnegativos. Este estudio confirma hallazgos que de otra manera no se hubiesen encontrado si no se hubiese investigado en esta área. "El que busca siempre encuentra".

\section{Referencias bibliográficas}

1.- Staphylococcus aureus, el patógeno persistente. En: Una historia personal de las bacterias. Ledermann W. Primera Edición. Ril Editores. 2007.

2.- Jevons M. Celbenin-resistant Staphylococci. Br Med J 1961; 1: 124-5.

3.- $\quad$ Leclerq R, Derlot E, Duval J, Courvalin P. Plasmid-mediated vancomycin and teicoplanin resistance in Enterococcus faecium. N Engl J Med 1988; 319: 157-61.

4.- Noble WC, Virani Z, Cree R. Co-transfer of vancomycin and other resistance genes from Enterococcus faecalis NCTC 12201 to Staphylococcus aureus. FEMS Microbiol Lett 1992; 93: 195-8.

5.- Hiramatsu K, Hanaki H, Ino T, Yabuta K, Oguri T, Tenover FC. Methicillin-resistant Staphylococcus aureus clinical strain with reduced vancomycin susceptibility. J Antimicrob Chemother 1997; 40 (1): 135-6.

6.- Centers for Disease Control and Prevention. Staphylococcus aureus resistant to vancomycin-United States, 2002. MMWR Morb Mortal Wkly Rep 2002; 51: 565-7.

7.- Rossi F, Díaz L, Wollam A, Panesso D, Zhou Y, Rincon S, et al. Transferable vancomycin resistance in a communityassociated MRSA lineage. N Engl J Med 2014; 370 (16): 1524-31.

8.- Sakoulas G, Moellering RC Jr. Increasing antibiotic resistance among methicillin-resistant Staphylococcus aureus strains. Clin Infect Dis 2008; 46 Suppl 5: S360-7.

9.- Otth L, Wilson M, Bustamante N, Fernández H, Otth C. Susceptibilidad antimicrobiana y patrones de resistencia de Staphylococcus aureus aislados de pacientes y portadores en la ciudad de Valdivia, Chile. Rev Chilena Infectol 2008; 25 (3): $175-8$.

Jaime Labarca

Departamento de Enfermedades Infecciosas del Adulto. Escuela de Medicina Pontificia Universidad Católica de Chile

Correspondencia a: Jaime A. Labarca Labarca jlabarca@med.puc.cl 